\title{
The Effect Of Social Networking Site Use On Fear Of Missing Out Through Self Regulation As A Mediator Variable
}

\author{
M Ravii Marwan* \\ ravii@staff.gunadarma.ac.id \\ Gunadarma University, Jl. Margonda Raya 100, Depok, 16424, Indonesia
}

\begin{abstract}
Fear of Missing Out (FoMO) is a feeling of fear of missing out on a precious moment about another individual or group in which that person cannot be present and is characterized by a desire to stay connected to what others are doing via the internet or social networks. So there is a need for research to measure the effect of Fear of Missing Out (FoMO), and how these influences affect FoMO, so that a theoretical model can be constructed.This study aims to explain the model of the influences that affect FoMO through self-regulation as a moderating variable. The research method uses quantitative methods. The data analysis technique used in this study is the structural equation model (SEM). The tool used to implement this analysis technique is the AMOS program. The results showed that the research model was stated in accordance with the data (goodness of fit). With the results of a significance level of $5 \%$, it proves that self-regulation is able to mediate the relationship between the influence of social networks on FoMO
\end{abstract}

Keywords: fear of missing out, social networking site, self regulation

\section{Introduction}

Social Network Sites (SNS) provide a platform for individuals to connect, share, and interact with one another, and have become the mainstay of social communication in today's era. Social networking sites are interesting because they have a function to build social identity and fulfill the need for popularity (Oberst, Renau, Chamarro, and Carbonell, 2016). One example of how the use of social networking sites has an impact on psychological and social experiences can be seen in the emergence of a new type of social anxiety commonly called fear of loss (FoMO). FoMO is described as a person's fear of missing out on social opportunities that drives them to stay connected with others and keep up to date with what others are doing (Przybylski et al, 2013). In recent years, the frequency and intensity of interactions with SNSs has become a significant cause of concern regarding the health and well-being of users. Problematic SNS use is increasingly considered a common public health problem worldwide. Kramer Guillory, and Hancock (2014) obtained results showing that when social network users view a lot of negative social network content, they are more likely to post negative content as well. The study also revealed the opposite, namely if someone more often sees content that contains positive content, the likelihood of posting positive content also increases. The results of research conducted by Alt (2016) show that increasing FoMO makes a person have negative emotions, low environmental mastery, and negative relationships with other people. Feelings of fear, anxiety and worry that arise make a person unable to control the environment, establish positive relationships with others, and self-acceptance (Beyens et al, 2016). Fulfillment of related needs through social networks has been shown to be positively correlated with Fear of Missing Out (FoMO) (Lai, Altavilla, Ronconi, \& Aceto, 2016). So it can be assumed that in the context of online behavior, individuals who have a tendency to FoMO will seek social acceptance by trying to stay connected with fellow social network users, to restore social bonds and feelings of connection with their friends. 
Research by Adams, Williford, Vaccaro, Kisler, Francis, \& Newman (2016). Users of social networking sites with high self-regulation will tend to choose to meet their long-term goals compared to their short-term goals by continuing to complete activities that are their long-term goals and delay opening their social networking site accounts. Before the long-term goal activities are completed. So that users of social networking sites will avoid problematic behavior in using the internet. Other literature also says that problematic behavior in internet use is caused by a lack of self-regulation (LaRose, Kim, \& Peng, 2009; Caplan, 2010). This happens because one of the sources of problematic behavior in internet use is the fact that the internet is able to provide instant gratification directly to individuals, such as being a means to regulate emotions, being an alternative communication for people with certain personality characteristics, which is where it can be obtained through social networking sites (Sebena, Orosova, \& Benka, 2013). Users of social networking sites with low self-regulation will tend to choose to satisfy the short term compared to the long term, which is tempted to open their social networking site account when they have to complete other activities. As a result, if this is done continuously, the use of social networking sites becomes excessive and eventually causes problematic behavior in internet use.

\section{Research Methods}

1.Can Self Regulation increase or decrease the effect of the intensity of Social Networking on Fear of Missing Out.

2. Is there a direct effect of the Self Regulation variable on Fear of Missing Out?

3. Is there a direct influence of the Social Networking Site on the Fear of Missing Out.

4. Indirect Effect of Social Networking Site on Fear of Missing Out with Self Regulation as Mediator.

There are 203 responden in this research, using the online media Google form filling method. The subjects were active students from semester 1 to semester 8 from various majors such as Communication, Management, Accounting, Information Systems, Industrial Engineering, Financial Management, Psychology and English Literature. Procedure The measuring instrument used in this research is the intensity scale of social network use, self-regulation scale and Fear of Missing Out scale. The data analysis technique used in this study is a structural equation model (SEM), the tool used to apply this analysis technique is the AMOS program.

\section{Results and Discussion}

Validity test

The validity test in this study used the Pearson product moment correlation with the help of SPSS ver 23 . The item value of the correlation coefficient used in this study was $<0.30$. If the item correlation coefficient is $<0.30$, it is considered invalid or omitted and is not used for research, while for items with a correlation coefficient $>0.30$ it is considered valid and used for research. The results of the validity test can be seen in the table below:

Pearson Correlation Validity Test

\begin{tabular}{ccc}
\hline \hline Indicator & $\begin{array}{c}\text { Pearson Correlation } \\
\text { Value }\end{array}$ & Information \\
\hline \hline SNS1 & 0,805 & Valid \\
SNS2 & 0,770 & Valid \\
SNS3 & 0,735 & Valid \\
SNS4 & 0,748 & Valid \\
SNS5 & 0,621 & Valid \\
\hline SR1 & 0,716 & Valid \\
SR2 & 0,687 & Valid \\
\hline \hline
\end{tabular}




\begin{tabular}{ccc}
\hline \hline SR3 & 0,855 & Valid \\
SR4 & 0,811 & Valid \\
SR5 & 0,768 & Valid \\
\hline FM1 & 0,773 & Valid \\
FM2 & 0,784 & Valid \\
FM3 & 0,760 & Valid \\
FM4 & 0,825 & Valid \\
FM5 & 0,805 & Valid \\
\hline \hline
\end{tabular}

In the validity test table above, it can be seen that all indicator items for each variable have a correlation coefficient value $>0.30$ which means that all indicators used in this research are declared valid. Furthermore, reliability test can be done.

\section{Reliability Test}

The reliability test in this study used the Cronbach Alpha coefficient approach $(\alpha)$ with the help of SPSS ver 23. The reliability results can be seen in the table below:

\begin{tabular}{c|c}
\hline \hline \multicolumn{2}{c}{ Reliability Statistics } \\
\hline \hline Cronbach's Alpha & N of Items \\
, 849 & 20 \\
& \\
\hline \hline
\end{tabular}

In the reliability test table above, it can be seen that the Croanbach's Alpha value is 0.849 . According to the Guilford criteria, the value of 0.849 is included in the range of values from 0.71 to 0.90 , which means that it has a high level of reliability for all indicator items.

\section{Confirmatory Factor Analysis (CFA) Test}

The validity test with the convergent validity test is to test the construct (indicator) whether it has a high proportion of variance or not. Meets the criteria if the loading factor value in the standardized loading estimate is greater than 0.5 . The results of the CFA test for each variable can be seen in the figure and table below:

CFA Variabel Social Networking Site

UJI MODEL

CHI-SQUARE: 4,783

SIGNIFIKANSI: , 091

DF: 2

GFI: ,988

AGFI: 942

CFI: 988

TLI: 964

RMSEA: ,083

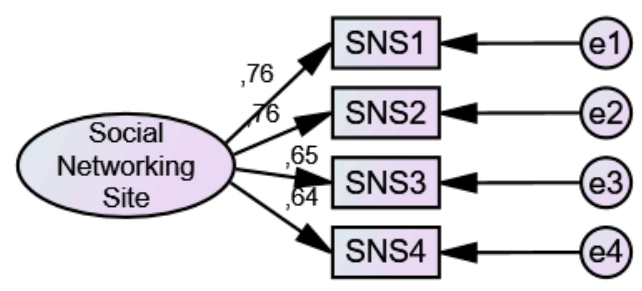



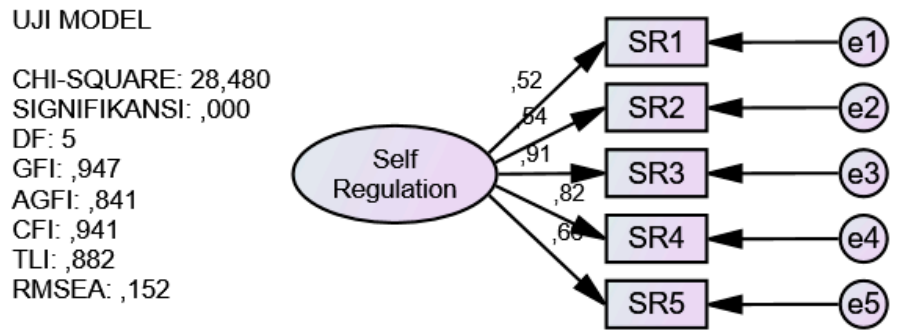

Hypothesis testing in this study uses regression weights, the criteria for hypothesis testing in this study are if the critical ratio $(\mathrm{CR})$ value $>1.96$ and $p$-value with a significant level comparison $(\alpha=5 \%)$ or $<0.05$ then the exogenous variable effect on endogenous variables, but if $\mathrm{CR}<1.96$ and p-value $>0.05$ then exogenous variables have no effect on endogenous variables, CR with $(* * *)$ three stars means very low value, namely $<0.001$.

In the table of Regression Weight and Standardized Regression Weights, it can be seen that Self Regulation has an effect on Fear of Missing Out (FoMo). This can be seen from the standardized coefficient value of 0.299 and a significance $(\mathrm{P})$ of $0.005<0.05$ or $\mathrm{CR} 2.838>1.96$ which means $\mathrm{H} 0$ is rejected and $\mathrm{H} 1$ is accepted. Based on these results, it can be stated that self-regulation has a positive and significant effect on fear of missing out (FoMO).

In the table of Regression Weight and Standardized Regression Weights, it can be seen that Social Networking Site has an effect on Fear of Missing Out (FoMo). This can be seen from the standardized coefficient value of 0.426 and the significance $(\mathrm{P}) * * *<0.05$ or CR $3.716>1.96$ which means $\mathrm{H} 0$ is rejected and $\mathrm{H} 2$ is accepted. Based on these results, it can be stated that self-regulation has a positive and significant effect on the fear of missing out (FoMO).

In the table of Regression Weight and Standardized Regression Weights, it can be seen that the Social Networking Site has an effect on Self Regulation. This can be seen from the standardized coefficient value of 0.650 and the significance $(\mathrm{P}) * * *<0.05$ or CR $6.064>1.96$ which means H0 is rejected and H3 is accepted. Based on these results, it can be stated that the social networking site has a positive and significant effect on self-regulation.

Regression Weight

\begin{tabular}{|c|c|c|c|c|c|c|}
\hline & & & Estimate & S.E. & C.R. & $P$ \\
\hline Self_Regulation & $<--$ & Social_Networking_Site & ,669 &, 110 & 6,064 & $* * *$ \\
\hline FoMo & $<--$ & Self_Regulation & ,434 &, 153 & 2,838 &, 005 \\
\hline FoMo & $<--$ & Social_Networking_Site & 637 & ,172 & 3,716 & $* * *$ \\
\hline
\end{tabular}

Standardized Regression Weight

\begin{tabular}{lllr}
\hline \hline & & & Estimate \\
\hline \hline Self_Regulation & $<---$ & Social_Networking_Site &, 650 \\
FoMo & $<---$ & Self_Regulation &, 299 \\
FoMo & $<---$ & Social_Networking_Site &, 426 \\
\hline \hline
\end{tabular}

1.In the table of Regression Weight and Standardized Regression Weights, it can be seen that Self Regulation has an effect on Fear of Missing Out (FoMo). This can be seen from the standardized coefficient value of 0.299 and a significance $(\mathrm{P})$ of $0.005<0.05$ or CR $2.838>1.96$ 
Based on these results, it can be stated that self-regulation has a positive and significant effect on the fear of missing out (FoMO). This shows that students who use social media such as whatsapp, facebook, intagram, line and others feel quite worried if they lose their moment and are not connected to others. In addition, they also experience anxiety about missing information on social media networks (SNS). These students are quite capable of overcoming the imbalance within themselves to meet the psychological needs of using social media. This situation makes students as social media users still able to control themselves, because in accessing social media they not only fulfill the need to connect with other people, but they also fulfill the need for entertainment and also to spend free time.

2. In the table of Regression Weight and Standardized Regression Weights, it can be seen that Social Networking Site has an effect on Fear of Missing Out (FoMo). This can be seen from the standardized coefficient value of 0.426 and the significance $(\mathrm{P}) * * *<0.05$ or $\mathrm{CR} 3.716>1.96$

Based on these results, it can be stated that self-regulation has a positive and significant effect on the fear of missing out (FoMO). This shows that students feel they have excessive fear if they do not use social media. With the advancement of technology, students have a curiosity about renewable technology with the new social media.

3. In the table of Regression Weight and Standardized Regression Weights, it can be seen that the Social Networking Site has an effect on Self Regulation. This can be seen from the standardized coefficient value of 0.650 and the significance $(\mathrm{P}) * * *<0.05$ or $\mathrm{CR} 6.064>1.96$

Based on these results, it can be stated that the social networking site has a positive and significant effect on self-regulation. This shows that students have a sense of dependence on social media. With the media, it makes a person more confident even if only by interacting and communicating with others through social media without having to meet in person or face to face in the real world. So that self-control on social media is very high, this is influenced by several factors including internal and external factors.

4. The test of the indirect effect of Social Networking Site (SNS) on Fear of Missing Out (FoMO) with Self Regulation as a mediator was carried out using the Sobel test.

Sobel Test

\begin{tabular}{|c|c|c|c|c|}
\hline Input: & & Test statistic: & Std. Error: & $p$-value: \\
\hline$a 0.669$ & Sobel test: & 2.57073623 & 0.11294274 & 0.01014826 \\
\hline$b 0.434$ & Aroian test: & 2.54266128 & 0.11418981 & 0.01100118 \\
\hline$s_{\mathrm{a}} 0.110$ & Goodman test: & 2.59976218 & 0.11168175 & 0.00932884 \\
\hline$s _ { b } \longdiv { 0 . 1 5 3 }$ & Reset all & & Calculate & \\
\hline
\end{tabular}

From the results of the Sobel test calculation above, the $\mathrm{z}$ value is 2.571 , because the $\mathrm{z}$ value obtained is $2.571>$ 1.96 with a significance level of $5 \%$, it proves that self-regulation is able to mediate the relationship between the influence of Social Networking Sites on Fear of Missing Out.

Based on these results, it can be seen that self-regulation can mediate the relationship between the influence of social networking sites (SNS) on Fear of Missing Out (FoMO). This is because in conducting self-regulation, students relate it to the Social Networking Site (SNS) level with Fear of Missing Out (FoMO). This can be seen from how much students use or check social media such as WA, Instagram, Facebook and others more than 3 times in 30 minutes.

\section{Conclusions and Suggestions}

The findings of this study indicate that students have a sense of dependence on social media. The existence of social media makes a person more confident even if only by interacting and communicating with others through social media without having to meet in person or face to face in the real world. The existence of social media has an impact on students to be able to control themselves in using social media by knowing the limitations that must be done to control the use of social media.

Based on the results of the research that has been conducted, there are some suggestions that can be given as follows:

- The results of this study found that SNS / social networking became the highest predictor which resulted in fear of missing out in students, for this reason it is necessary to reduce the activity of using social networks through smartphones.

- In this study, there are still shortcomings, especially in taking the number of samples for respondents due to the conditions that are being passed by the world, namely the Covid-19 Pandemic. 
- $\quad$ Further research can add and consider personality type as a predictor variable of social media use, as stated by Teresa Correa (2013) that emotional stability is a negative predictor of social network use.

\section{References}

Adams, S. K., Williford, D. N., Vaccaro, A., Kisler, T. S., Francis, A., \& Newman, B. (2017). The young and the restless: Socializing trumps sleep, fear of missing out, and technological distractions in first-year college students. International Journal of Adolescence and Youth, 22(3), 337-348.

Alt, D. (2017). Students' social media engagement and fear of missing out (FoMO) in a diverse classroom. Journal of Computing in Higher Education, 29(2), 388-410.

Beyens, I., Frison, E., \&Eggermont, S. (2016). "I Don't Want To Miss A Thing”: Adolescents' Fear Of Missing Out And Its Relationship To Adoescents' Social Need, Facebook Use, And Facebook Related Stress.Computers in Human Behavior.

Kramer, A. D., Guillory, J. E., \& Hancock, J. T. (2014). Experimental evidence of massive-scale emotional contagion through social networks. Proceedings of the National Academy of Sciences, 111(24), 8788-8790.

Lai, C., Altavilla, D., Ronconi, A., \& Aceto, P. (2016). Fear of missing out (FOMO) is associated with activation of the right middle temporal gyrus during inclusion social cue. Computers in Human Behavior, 61, 516-521.

LaRose, R., Kim, J., \& Peng, W. (2010). Social networking: Addictive, compulsive, problematic, or just another media habit?. In $A$ networked self (pp. 67-89). Routledge.

Oberst, U., Renau, V., Chamarro, A., \& Carbonell, X. (2016). Gender stereotypes in Facebook profiles: Are women more female online?. Computers in Human Behavior, 60, 559-564.

Przybylski, A. K., Murayama, K., DeHaan, C. R., \& Gladwell, V. (2013). Motivational, emotional, and behavioral correlates of fear of missing out. Computers in human behavior, 29(4), 1841-1848.

Sebena, R., Orosova, O., \& Benka, J. (2013). Are self-regulation and depressive symptoms predictors of problematic Internet use among first year university students?. PsychNology Journal, 11(3).

Sugiyono. (2014). Metode penelitian pendidikan pendekatan kuantitatif, kualitatif, dan R\&D. Bandung: Alfabeta.

Sugiyono. (2017). Metode penelitian sosial. Bandung: PT Remaja Rosdakarya. 